\title{
AS DIMENSÕES EDUCACIONAL E POLÍTICA DA SOCIEDADE DA INFORMAÇÃO
}

\author{
Fabiano Couto Corrêa da Silva
}

\begin{abstract}
Resumo
Apresenta uma abordagem sobre as dimensões educacional e política da sociedade da informação, discutindo um cenário de mudanças constantes em decorrência do uso da informação por meio das novas tecnologias, em especial a Internet. Ressalta o Grupo Temático de Educação do Livro Verde e o atual panorama dos níveis educacionais e de acesso à informação no Brasil.
\end{abstract}

\section{Palavras-Chave}

Sociedade da Informação; Educação; Inclusão Digital; Tecnologia da Informação; Livro Verde.

\section{INTRODUÇÃO}

Este trabalho apresenta algumas reflexões sobre a posição de relevo que a sociedade da informação vai assumindo no Brasil, buscando caracterizar os mecanismos e influências que a sustentam.

A partir de uma revisão teórica sobre a dimensão educacional e política do discurso constituinte desta sociedade, o trabaIho insere a informação como peça de sustentação para a formação de uma nova estrutura de mudanças de processos sociais. Trata-se de um estudo exploratório, que procura extrair alguns problemas e perspectivas para a consolidação de uma sociedade informacional, especialmente no caso brasileiro. Para tanto, é discutido a complexidade que envolve o surgimento de uma sociedade midiática e mais crítica, na medida em que são construídos espaços que proporcionam acesso às informações necessárias para sua formação.

Inicialmente são abordados aspectos relativos à concepção da sociedade da informação, observando-se a importância da informação para o desenvolvimento da sociedade e o processo de transformações causadas pelas tecnologias informacionais.

Para o desenvolvimento da pesquisa sobre o tema, observa-se o papel do Estado como gestor do desenvolvimento para a criação desta nova sociedade e as estraté- 
gias adotadas com o objetivo de criar oportunidades para a consolidação da sociedade da informação através de políticas educacionais.

A partir de análise da linha de ação do Livro Verde referente à educação, apresenta-se um exame do atual cenário brasileiro sobre as oportunidades de acesso ao ensino e às mídias eletrônicas através de incentivos de ONGs e do Estado.

Por fim, estes dados são verificados buscando-se comparar as propostas do Livro Verde com a realidade apresentada por dados estatísticos de órgãos governamentais e o apontamento de alguns projetos inovadores que fornecem subsídios ao desenvolvimento da sociedade da informação no Brasil.

\section{A CONCEPÇÃO DA SOCIEDADE DA INFORMAÇÃO}

As transformações sociais causadas pelo advento de novas tecnologias geraram uma revolução informacional que foi amplamente discutida por muitos autores através de uma história recente de mudanças na forma como nos relacionamos por meio das novas mídias eletrônicas. McLuhan e Fiore (1967) lançaram o conceito de Aldeia Global como maneira de descrever o surgimento das novas tecnologias que influenciam as formas de comunicação entre as pessoas; conforme Bell (1977), vivemos em uma sociedade pós-industrial;
Toffler (1980) nos diz que mergulhamos na terceira onda, em que o conhecimento adquire importância extrema; Drucker (1994) afirma que atingimos a sociedade do conhecimento; Negroponte (1995) revela que presenciamos uma sociedade digital; Lévy (2000) aponta para um universo coletivo de inteligência compartilhada e, de acordo com Castells (1999), podemos dizer que caminhamos para a concretização de uma sociedade verdadeiramente informacional através da sociedade em rede.

Podemos ver que, para diversos autores, a informação assume finalidades específicas no âmbito social. Desse modo, a informação adquire importância como um recurso fundamental para o desenvolvimento da sociedade, gerando conhecimento, e este, por sua vez, gerando mais informação. Mas, como podemos conceituar a informação na atual sociedade que vivemos?

De acordo com o Dicionário On-line de Biblioteconomia e Ciência da Informação - ODLIS (2006), "Informação é um dado apresentado de forma compreensível para leitura e com um contexto atribuído para seu uso. E indica a idéia que uma mensagem específica é informativa ou não dependendo da percepção subjetiva da pessoa que a recebe". Assim, o termo informação pode ser usado num contexto muito amplo, que vai além do seu uso cotidiano pela sociedade, como acesso ao co- 
nhecimento sobre eventos e objetos, não se limitando a dados coletados.

Drucker (1994, p. 18) definiu informação como "dados dotados de relevância e propósito". Quem os dota de tais atributos? A própria sociedade. Até mesmo quando um computador, automaticamente, transforma uma folha de custos num gráfico mais informativo, como as "pizzas", alguém tem que escolher como representar esse desenho. Hoje, a informação passou a ter um valor altamente significativo para as pessoas e instituições. Ela tem grande valor, uma vez que está presente em todas as atividades que envolvem pessoas, processos, sistemas, recursos financeiros, tecnologias, entre outros. Assim, a informação passa a ser um recurso sinérgico: quanto mais a temos, mais a usamos e mais útil se torna. Ou, como descreve Morin (1991, p. 27), na sociedade da informação imergimos em uma sociedade midiatizada em que "os indivíduos produzem a sociedade e essa produz os indivíduos, onde o todo está na parte e a parte está no todo".

No aspecto cognitivo, a sociedade da informação coloca o indivíduo como receptor e ao mesmo tempo, gerador de novas informações por meio das impressões que recebe a todo o momento por diferentes mídias, sejam eletrônicas ou não. Nesse sentido, o valor da informação é um conceito muito relativo: nem toda informação apresenta a mesma importância para uma decisão e, se não for comunicada às pessoas interessadas em forma e conteúdo adequados, ela pode perder o seu valor. Desse modo, percebemos que "a informação é um fator que se relaciona com o conhecimento humano, onde pode ser considerada como fator de modificação e integração entre o homem e a sociedade" (CAPURRO, 2006).

No Brasil, a sociedade da informação configura-se como resultante das aplicações das tecnologias de informação e comunicação, as quais têm auxiliado a personalização das informações nesta nova sociedade que está sendo construída. Essas tecnologias podem, de acordo com diversas bases de dados, gerar informações e conhecimento relevantes, auxiliando a busca perspectivas e alternativas de negócios no mercado e na geração de pesquisas. Enfim, o que vemos são possibilidades ilimitadas de socialização da informação e que podem ser aplicadas a diferentes setores culturais, educacionais e políticas públicas, assim como é previsto no Livro Verde.

\section{O LIVRO VERDE NO BRASIL}

Para acompanhar as transformações nas tecnologias informacionais, o governo brasileiro tem adotado medidas importantes com o intuito de ampliar o desenvolvimento de novas práticas educacionais, 

como a elaboração do Programa Sociedade da Informação no Brasil - Livro Verde, que indica o desenvolvimento de competências para atuar efetivamente

[...] na produção de bens e serviços, tomar decisões fundamentadas no conhecimento, operar com fluência novos meios e ferramentas em seu trabalho, bem como aplicar criativamente as novas mídias, seja em uso simples e rotineiro, seja em aplicações mais sofisticadas. (TAKAHASHI, 2000, p.45).

As ações necessárias para a implantação do Programa Sociedade da Informa- ção, apresentadas no Livro Verde, têm o objetivo de promover o acesso às novas tecnologias no Brasil e capacitar a população ao domínio necessário para buscar e utilizar a informação no mercado e para o enriquecimento cultural da sociedade. Para

a consolidação da sociedade da informação, prevê serviços de informação por intermédio de sete linhas de ação, conforme demonstrado no quadro a seguir com suas respectivas finalidades:

Quadro 1 - Linhas de Ação do Programa Sociedade da Informação

\begin{tabular}{|c|c|}
\hline Linhas de ação & Descrição \\
\hline $\begin{array}{l}\text { Mercado, trabalho e oportuni- } \\
\text { dades }\end{array}$ & $\begin{array}{l}\text { Promoção de competitividade das empresas e expansão das pequenas e mé- } \\
\text { dias empresas; apoio à implantação de comércio eletrônico e oferta de novas } \\
\text { formas de trabalho, por meio do uso intensivo de tecnologias de informação e } \\
\text { comunicação. }\end{array}$ \\
\hline $\begin{array}{l}\text { Universalização de serviços e } \\
\text { formação para a cidadania }\end{array}$ & $\begin{array}{l}\text { Promoção da universalização do acesso à Internet, buscando soluções alterna- } \\
\text { tivas, com base em novos dispositivos e meios de comunicação; promoção de } \\
\text { modelos de acesso coletivo ou compartilhado à Internet e fomento a projetos } \\
\text { que promovam a cidadania e a coesão social. }\end{array}$ \\
\hline $\begin{array}{l}\text { Educação para a sociedade } \\
\text { da informação }\end{array}$ & $\begin{array}{l}\text { Apoio aos esquemas de aprendizado, de educação continuada e a distância } \\
\text { baseados na Internet e em redes, por meio de fomento ao ensino, auto- } \\
\text { aprendizado e certificação em TIC; implantação de reformas curriculares visan- } \\
\text { do ao uso das TICs em atividades pedagógicas e educacionais, em todos os } \\
\text { níveis da educação formal. }\end{array}$ \\
\hline $\begin{array}{l}\text { Conteúdos e identidade cultu- } \\
\text { ral }\end{array}$ & $\begin{array}{l}\text { Promoção da geração de conteúdos e aplicações que enfatizem a identidade } \\
\text { cultural brasileira e as matérias de relevância local e regional; fomento a es- } \\
\text { quemas de digitalização para a preservação artística, cultural, histórica, e de } \\
\text { informações de C\&T, bem como a projetos de P\&D para geração de tecnologi- } \\
\text { as com aplicação em projetos de relevância cultural. }\end{array}$ \\
\hline Governo ao alcance de todos & $\begin{array}{l}\text { Promoção da informatização da administração pública e do uso de padrões nos } \\
\text { seus sistemas aplicativos; concepção, prototipagem e fomento à aplicações em } \\
\text { serviços de governo, especialmente os que envolvem ampla disseminação de } \\
\text { informações; fomento à capacitação em gestão de tecnologias de informação e } \\
\text { comunicação na administração pública. }\end{array}$ \\
\hline $\begin{array}{l}\text { P\&D, tecnologias-chave e } \\
\text { aplicações }\end{array}$ & $\begin{array}{l}\text { Identificação de tecnologias estratégicas para o desenvolvimento industrial e } \\
\text { econômico e promoção de projetos de P\&D aplicados a essas tecnologias nas } \\
\text { universidades e no setor produtivo; concepção e indução de mecanismos de } \\
\text { difusão tecnológica; fomento a aplicações piloto que demonstrem o uso de } \\
\text { tecnologias-chave; promoção de formação maciça de profissionais, entre eles } \\
\text { os pesquisadores, em todos os aspectos das TIC. }\end{array}$ \\
\hline Infra-estrutura avançada & $\begin{array}{l}\text { Implantação de infra-estrutura de informações, integrando as diversas redes - } \\
\text { governo, setor privado e P\&D; adoção de políticas e mecanismos de segurança } \\
\text { e privacidade; fomento à implantação de redes de processamento de alto de- } \\
\text { sempenho e à experimentação de novos protocolos e serviços genéricos; trans- } \\
\text { ferência acelerada de tecnologia de redes do setor de P\&D para as outras re- } \\
\text { des e fomento à integração operacional. }\end{array}$ \\
\hline
\end{tabular}

Fonte: TAKAHASHI (2002) 
As linhas de ação propostas fazem parte de um amplo planejamento que tem como objetivo atingir a comunidade científica, auxiliar a indústria, o comércio, e a sociedade em geral. No entanto, para alcançar as metas propostas no Livro Verde o governo enfrentará grandes obstáculos para colocar a sociedade na direção de uma sociedade informacional, como é previsto no debate acerca do planejamento para tornar o acesso à informação mais amplo e homogêneo entre as diferentes classes sociais.

O grupo temático de educação do Livro Verde prevê a incorporação das tecnologias de informação e comunicação como complemento às atividades pedagógicas. É uma proposta que inclui muitos obstáculos, devido ao cenário de desigualdades sociais na educação e na forma como essas tecnologias são utilizadas como recurso para o ensino. Como presume Werthein (2000, p. 77)

Seria indispensável identificar o papel que essas novas tecnologias podem desempenhar no processo de desenvolvimento educacional e, isso posto, resolver como utilizá-las de forma a facilitar uma efetiva aceleração do processo em direção à educação para todos, ao longo da vida, com qualidade e garantia de diversidade.

Nesse sentido, Mattelart (2002, p. 173) observa que "a sociedade das redes está longe de ter colocado um fim ao etnocentrismo dos tempos imperiais. Em vez de resolver o problema, a tecnologia o deslo- ca." E vai além, ao afirmar que a tecnologia impõe uma nova maneira de sobrevivência, porque divide o mundo entre os lentos e rápidos. Essa afirmativa vai ao encontro da visão de Baggio (2000, p. 16) quando aponta que

Em plena era da informação, é fundamental que se democratizem as ferramentas tecnológicas, um dos principais requisitos do novo mercado de trabalho, para que os novos recursos de comunicação e tecnologia não se transformem em um fator de aprofundamento de exclusão social.

Dessa maneira, não se pode negar a importância das tecnologias da informação nas políticas educacionais. O problema está no dimensionamento dado ao papel da tecnologia no desenvolvimento do aprendizado por meio de diretrizes que contemplem as necessidades sociais. Entre as propostas apresentadas no Programa Sociedade da Informação, lançado em 1999 pelo governo federal, está a de incentivo à pesquisa e à educação, de forma que o Brasil tenha condições de maior participação no cenário internacional. Ao analisar a literatura sobre a sociedade da informação, percebe-se que apesar de sua definição estar em permanente construção, existe um consenso visível: as tecnologias da informação e a linguagem como é transmitida (NEHMY; PAIM, 2002). Do mesmo modo, Silva (2001, p. 5) destaca que A Sociedade da Informação está
voltada para o uso das tecnologias
de informação e comunicação e
uma de suas características é a 
capacidade de produção de informações em quantidade e diversidade. Esta realidade reflete diretamente na educação, uma vez que, o material utilizado no processo de ensino-aprendizagem passa a ser complementado pela tecnologia. Dessa forma, as técnicas de ensino voltadas para a mecanicidade são insuficientes para a preparação do cidadão mediante a Sociedade da Informação, em que pressupõe a capacidade de utilização dos novos recursos informacionais disponíveis.

Mattelart (2002, p.163) observa que, de acordo com a UNESCO, "a educação de base e a alfabetização são prérequisitos para o acesso universal ao ciberespaço". A relevância desse apontamento no atual cenário educacional em que vivemos é significativa, pois o aprendizado no ambiente virtual proporciona múltiplas possibilidades e formas de interagir com a tecnologia, como digitar textos, fazer cálculos, trabalhar com imagens e gráficos, elaborar planilhas de contas. Por outro lado, Mattelart (2002) traz à tona uma importante questão, que diz respeito ao desenvolvimento e acesso ao ciberespaço, descrevendo que as regiões que possuem uma sociedade com problemas de infraestrutura de recursos humanos e tecnológicos ficam à margem da revolução tecnológica, sendo aquilo que o Jornalista e educador Gilberto Dimenstein ${ }^{1}$ chamou de "analfabetos digitais".

\footnotetext{
${ }^{1}$ Criador do projeto Aprendiz (ONG voltada para a pesquisa e desenvolvimento do ensino). Disponível no endereço: <http://www.aprendiz.org.br>. Acesso em: 14 jul. 2006.
}

4 O QUE DIZEM OS NÚMEROS NO CENÁRIO BRASILEIRO

De acordo com pesquisa realizada pelo Instituto Paulo Montenegro (IPM), braço social do Grupo IBOPE, sobre dados coletados em 2005 e divulgados pelo Indicador de Alfabetismo Funcional - INAF (2006), somente $26 \%$ da população brasileira na faixa de 15 a 64 anos de idade são plenamente alfabetizados. O INAF aponta ainda que $30 \%$ estão no Nível Rudimentar, ou seja, conseguem ler títulos ou frases, localizando uma informação bem explícita, e somente $6 \%$ deles usam computadores, mas $52 \%$ dizem ler jornais e $48 \%$, revistas. Outros $38 \%$ dos brasileiros estão no Nível Básico de alfabetismo. Esses conseguem ler textos curtos, localizando uma informação explícita ou que exija uma pequena inferência. As principais deficiências estão concentradas entre pessoas das classes $C$, D e E. Nesse nível, $60 \%$ das pessoas têm ao menos o ensino médio completo, 54\% usam computadores, $83 \%$ dizem ler jornais e $84 \%$, revistas.

Dados fornecidos pelo Núcleo de Informação e Coordenação do Ponto br, entidade executora do Comitê Gestor da Internet no Brasil, indicam que ocupamos até o ano de 2006, o $9^{\circ}$ lugar no ranking mundial do número de domínios registrados e cerca de 14,1 milhões de brasileiros utilizaram a Internet em suas residências até o mês de março de 2006. Pesquisa divulga- 
da recentemente pelo IBOPE/Net Ratings, indica que o tempo on-line no mês de maio de 2006 foi recorde, com $20 \mathrm{~h}$ e $25 \mathrm{~min}$, superando países como a França (que estava à frente do Brasil na pesquisa divulgada anteriormente), Japão e Estados Unidos.

Já no ranking da União Internacional de Telecomunicações, órgão da ONU que mede o acesso dos cidadãos de 180 nações à sociedade da informação por intermédio do Índice de Oportunidade digital, o Brasil ocupa a $71^{\text {a }}$ posição.

Pesquisa trimestral do relatório "Indicador da Sociedade da Informação", realizada pela DMR Consulting (2006), em parceria com o IESE Business School, indica que o Brasil e a América Latina estão muito distantes dos chamados países pobres do primeiro mundo no uso da Tecnologia da
Informação. Conforme Lobo (2006), em decorrência do ambiente econômico, o Brasil ficou atrás do Chile, México e Argentina. Esse estudo tem o objetivo de avaliar quais serão os impactos da tecnologia no cotidiano das pessoas, prever e monitorar o crescimento da Sociedade da Informação em diferentes regiões, além de comparar os resultados nos países pesquisados e traçar expectativas para o próximo período.

De acordo com o censo de 2000 divulgado pelo IBGE, a população de brasileiros com acesso doméstico ao uso do computador corresponde a 16.209.223.00. O gráfico divulgado apresenta um total de 169.872.850 pessoas, sendo que a soma dos excluídos digitais chega a 153.663.627. Com base nesses dados, a Fundação Getúlio Vargas (FGV) criou o Mapa Social do Brasil, que descreve fatores e estatísticas sobre a exclusão digital.

Tabela 1: Mapa Social

\begin{tabular}{cccccccc}
\hline Universo & População Total & Homens \% & Educação* & Idade* $^{*}$ & PIA $^{* *}$ & Renda* $^{*}$ & Jornada* $^{*}$ \\
Incluídos & 16209223.00 & 48.89 & 8.72 & 31.14 & 462826.66 & 1677.15 & 41.76 \\
Excluídos & 153663627.00 & 49.25 & 4.40 & 27.95 & 529046.90 & 452.44 & 43.40 \\
Brasil/Total & 169872850.00 & 49.21 & 4.81 & 28.26 & 522728.18 & 569.30 & 43.24 \\
\hline
\end{tabular}

Fonte: FUNDAÇÃO GETÚLIO VARGAS (2003)

Levando-se em conta que a tabela demonstra a maior parte da população excluída do acesso às tecnologias informacionais, se torna evidente a tendência que estes fiquem cada vez mais à margem da sociedade da informação. Na medida em que as demandas informacionais aumentam, também cresce a necessidade de no- vos projetos que disponibilizem o acesso à informação para a sociedade brasileira.

\footnotetext{
* Os valores referentes a essas variáveis são médias. A variável educação refere-se aos anos médios de estudo, jornada refere-se à jornada de trabalho semanal e a renda do trabalho principal referente à população ocupada.

** População em idade ativa (PIA) refere-se às pessoas entre 15 e 65 anos.
} 


\section{ALGUNS PROJETOS INOVADORES}

Para diminuir as deficiências de acesso às novas tecnologias, a Cúpula Mundial da Sociedade da Informação, evento que teve a primeira fase em Genebra no ano de 2003 e a segunda fase na Tunísia em 2005 , estabeleceu uma carta com um plano de ações necessárias para a consolidação da sociedade da informação. De acordo com Branco (2003), a primeira fase do evento ficou marcada "pelas diferenças profundas de interesses entre os representantes dos governos dos países ricos e o bloco de países em desenvolvimento e pobres liderados pelo Brasil, Índia, África do Sul, China, Egito e Argentina". Na carta escrita na segunda fase, entre outras indicações, afirma a importância do papel do estado na criação de políticas públicas para o acesso à informação por intermédio da inclusão digital e destaca a importância que as organizações não-governamentais (ONGs) possuem como catalisadoras de recursos e de esforços para os empreendimentos direcionados à inclusão digital, a fim de ampliar as possibilidades de consolidação e crescimento da sociedade da informação.

Existem também políticas mais direcionadas ao planejamento de ações que visam o impulsionamento de atividades de inserção da sociedade brasileira a um acesso mais democrático à informação, como é o caso do Programa eLAC 2007
(2006). As metas relacionadas ao desenvolvimento da sociedade da informação na América Latina e Caribe foram apresentadas em 2005 na Cúpula Mundial da Sociedade da Informação, prescrevendo metas e ações a serem seguidas para consolidar a sociedade da informação nesta região.

Uma iniciativa que tem demonstrado sucesso no combate ao analfabetismo no Brasil é o projeto Alfabetização Solidária, um programa de alfabetização de jovens e adultos gerenciado por uma ONG sem fins lucrativos que trabalha em parceria com empresas, prefeituras, governos e instituições de ensino superior para oferecer educação para jovens e adultos. De acordo com Holanda e colaboradores. (2006, p. 11), "está presente em 2.066 municípios brasileiros, atuando prioritariamente em áreas pobres, que possuem os maiores índices de analfabetismo definidos em ranking do IBGE".

Por outro lado, mesmo havendo iniciativas como as mencionadas, o estado não deve ficar isento de adotar políticas educacionais que contemplem o acesso às tecnologias de comunicação aos estudantes. Como observa Ferreira (2003, p. 38), "nas escolas públicas pouco se inovou nos métodos de ensino diante das possibilidades ainda inexploradas de aprendizado oferecidas pelas novas tecnologias de comunicação e informação [...]". 
A dimensão educacional e política em torno de investimentos acerca da consolidação da sociedade da informação no Brasil deve contemplar formas de integrar a inclusão digital em torno do acesso e instrução às novas tecnologias e, em especial a Internet. Nesse sentido, Vogt (2001) observa que:

As perorações dos sacerdotes do novo credo formam arengas que, pela recitação insistente, vão constituindo como que mantras de verdades oraculares: novo paradigma tecno-econômico, resgatar a dívida social, alavancar o desenvolvimento, constituir uma nova ordem social, excluir a exclusão, economia baseada na informação, no conhecimento e no aprendizado, "onda de destruição criadora", evitar que se crie classe de "info-excluídos", alfabetização digital, fluência em tecnologia da informação e comunicação, aprender a aprender, inclusão social como prioridade absoluta, democratização dos processos sociais pelas tecnologias da informação, vencer a clivagem social entre o formal e o informal, agregação de valor, redes de conteúdos que farão a sociedade mover-se para a sociedade da informação, educação a distância, igualdade de oportunidades de acesso às novas tecnologias, condição indispensável para a coesão social no Brasil.

Há mais! Mas a amostra basta para dar uma idéia do curso das águas claras desse pensamento simplista que constitui o ideário ambicioso da sociedade global da informação.

Essa avaliação de Vogt (2001) demonstra a complexidade de obstáculos que devem ser superados para que tenhamos uma sociedade com maior acesso à Internet e vai ao encontro das observações de Miranda e Mendonça (2006, p. 5)
A exclusão digital é um fenômeno complexo e de várias dimensões. $\mathrm{O}$ incentivo somente ao desenvolvimento tecnológico não é suficiente para superá-la, sendo necessário também incentivar a democratização da informação, ampliando o acesso do cidadão aos espaços públicos de produção e divulgação do conhecimento, e melhorar a distribuição de renda, assim como o desenvolvimento dos recursos humanos locais e a construção de uma rede digital rizomática. É preciso que cada ponto se transforme em uma base que possa desencadear novos pontos, estruturados nas relações coletivas, e constituídos a partir de suas necessidades e características, assim como de demandas provenientes dos cenários nacional e mundial, interligando cada grupo, desde suas raízes locais, permitindo o trânsito em mão dupla do conhecimento.

Embora ocorra uma disparidade muito grande entre o crescimento do número de pessoas alfabetizadas e as que dominam o uso da informática, existem muitos programas de acesso público e em desenvolvimento para o uso das Tecnologias da Informação e Comunicação. Isto pode ser observado em projetos sociais como o Programa Nacional de Informática na Educação (PROINFO), a TV Escola e o Telecurso 2000, que buscam promover o uso da Telemática como ferramenta de enriquecimento pedagógico no ensino público fundamental e médio. Existe também a Universidade Virtual Pública do Brasil (UniRede), que é um consórcio de instituições públicas de ensino superior envolvendo 70 universidades, além do programa do Ministério da Cultura (MINC) para in- 
formatização do acervo da Biblioteca Nacional.

O Comitê para Democratização da Informática (CDI), uma ONG criada em 1993, oferece "acesso às tecnologias de informação aos membros de comunidades pobres, principalmente crianças e jovens, além de cegos, doentes mentais, deficientes físicos, presos e minorias étnicas" (BAGGIO, 2000, p. 17), proporcionando o uso de recursos essenciais para a inclusão destas pessoas na sociedade da informação.

Outra iniciativa bastante interessante é o Projeto Casa Brasil (2006), um empreendimento do Governo Federal que reúne esforços de diversos ministérios, órgãos públicos, bancos e empresas estatais para levar inclusão digital, cidadania, cultura e lazer às comunidades de baixa renda por intermédio telecentros, auditórios, biblioteca popular, espaços multimídia, laboratório de informática e oficina de rádio. $\mathrm{O}$ objetivo é oferecer ao público diversos módulos em que se realizam atividades em torno dos temas Inclusão Digital e Sociedade da Informação. Nesses espaços, as pessoas podem fazer uso intensivo das tecnologias da informação e da comunicação. Isso irá capacitar os segmentos excluídos da população para a inserção crítica na sociedade da informação, buscando superar e romper a cadeia de reprodução da pobreza.

\section{O CAMINHO PERCORRIDO}

Como vimos, existem muitos projetos de inclusão digital, tanto no âmbito da iniciativa privada quanto da pública, causando enorme impacto social e cultural na forma como nos relacionamos, transmitimos e recebemos informações para o ensino e a aprendizagem.

Embora esteja longe de atingir as classes menos favorecidas em sua totalidade, o Brasil apresenta um círculo virtuoso de avanços no uso intensivo das tecnologias informacionais nas escolas e no ensino superior por meio da criação de novos espaços de acesso público, políticas educacionais e de implantação e desenvolvimento tecnológico. Um exemplo, como foi exposto neste trabalho, seria o Livro Verde, apresentado como uma oportunidade de transformações, mas que ainda caminha lentamente para a concretização de um projeto que talvez não seja nenhuma garantia de que as propostas apresentadas irão ocorrer na prática.

O Livro Verde demonstra maior ênfase na tecnologia que na inclusão social dos "analfabetos digitais", deixando a sociedade, de modo geral, condicionada ao acesso tecnológico sem reestruturação curricular do ensino, que deveria passar pela inserção dos educadores na reestruturação de um novo modelo de ensino e aprendizagem. Desse modo, a concepção da sociedade da informação deveria vir nesta or- 
dem: inclusão social para depois haver inclusão digital.

Bunge (1980), argentino, historiador e filósofo da ciência, questiona se é possível realizar pesquisa básica em um país subdesenvolvido. Fazendo relação entre ciência e sociedade, demonstra a relação existente entre a ciência e os problemas nacionais, refletindo se a ciência seria um luxo ou uma necessidade. Dessa forma, Bunge (1980) apresenta esta questão de um ponto de vista epistemológico, o que significa dizer que a política científica no Brasil carece de definição sobre o que se quer com o desenvolvimento científico. Uma amostra disso seria a falta de esclarecimento sobre a definição de recursos para a execução do Livro Verde e que parece deixar sua aplicação bem distante da realidade em termos de planejamento. Nesse sentido, vemos o surgimento de muitos telecentros e a ampliação do acesso às mídias eletrônicas serem criados como forma de fornecer à sociedade, amplo acesso á informação.

No entanto, essas "ilhas tecnológicas" não bastam para combater a exclusão digital, especialmente no atual cenário da globalização, que necessita de planejamento integrado entre educação, ciência e tecnologia. Neste caso, uma educação de qualidade com o uso da informática poderia diminuir a exclusão digital e preparar o futuro cenário para que os brasileiros tenham a- cesso às tecnologias de informação e comunicação, consolidando a sociedade da informação.

Os poderes público e privado têm modificado muito o regime de desigualdades sociais por meio da criação e capacitação de novos espaços tecnológicos e práticas pedagógicas. Porém, vale destacar que as políticas educacionais têm sido realizadas no Brasil de forma fragmentada, não havendo a adoção de um plano diretor para o desenvolvimento de ideologias, como é o caso do Livro Verde.

O Livro Verde pode ser efetivamente uma oportunidade de transformação. Embora o projeto não traga a garantia de investimentos, é uma oportunidade que deve ser discutida e aproveitada como base para planejar o futuro da educação no Brasil. Trata-se de um livro que aponta novos caminhos, mas que ainda carece de seguidores.

\section{CONSIDERAÇÕES FINAIS}

Neste artigo, buscou-se uma definição para a sociedade da informação, de modo que os argumentos para sua consolidação pudessem ser analisados por intermédio dos indicadores sociais de educação e acesso às tecnologias disponibilizadas por órgãos de avaliação do nível educacional brasileiro. 
No Brasil, percebe-se que nos últimos anos a inclusão digital tem sido considerada uma das prioridades para o desenvolvimento da sociedade da informação, e que a necessidade de criar meios que proporcionassem o acesso às tecnologias informacionais de forma mais concreta surtiu efeito positivo na educação dos indivíduos. Porém, a inclusão digital no Brasil ainda está longe de atingir a dimensão informacional que a sociedade da informação anuncia.

Ao mesmo tempo em que são criados novos espaços de acesso às tecnologias informacionais, aumenta a estatística dos "analfabetos digitais", os que ficam à margem do desenvolvimento educacional. A nova interdependência eletrônica criada pela conexão entre "diferentes saberes", por meio de um mundo linear, especializado e visual, e um mundo simultâneo, holístico e multissensorial propiciado pelo hipertexto, impõe novas formas cognitivas de aprendizagem na interação entre o indivíduo e o mundo virtual.

Por fim, podemos dizer que junto à inclusão digital, deve haver o acompanhamento educacional de forma que os conteúdos curriculares estejam integrados ao processo de construção do conhecimento. Do contrário, não adiantará haver a inclusão digital se o indivíduo não deixar de ser apenas um passivo consumidor de informações.

\section{REFERÊNCIAS}

BAGGIO, Rodrigo. A sociedade da informação e a infoexclusão. Ciência da Informação, vol.29, n.2, p.16-21, maio/ago. 2000.

BELL, Daniel. O advento da sociedade pós-industrial: uma tentativa de previsão social. São Paulo: Cultrix, 1977.

BRANCO, Marcelo D'Elia. Os ricos e o "resto do mundo". Cúpula da Sociedade da Informação em Genebra. Disponível em: <http://www.softwarelivre.org/articles/51> Acesso em: 14 jul. 2006.

BUNGE, Mario. Ciência e desenvolvimento. Belo Horizonte, Itatiaia/Edusp, 1980.

CAPURRO, Rafael. Epistemologia e Ciência da Informação. Disponível em <http://www.capurro.de/enancib_p.htm>. Acesso em: 26 ago. 2006.

CASTELLS, Manuel. A sociedade em rede. 2. ed. São Paulo: Paz e Terra, 1999. v.1

DICIONÁRIO On-line de Biblioteconomia e Ciência da Informação (ODLIS). Disponível em: <http://lu.com/odlis/>. Acesso em: 25 ago. 2006.

DRUCKER, Peter. Sociedade póscapitalista. São Paulo: Pioneira, 1994.

The coming of the new organization. Harvard Business Review v. 66, p. 4553, Jan./Feb. 1998,

FERREIRA, Rubens da Silva. Ciência da Informação. Brasília, v. 32, n. 1, p. 36-41, jan./abr. 2003

FUNDAÇÃO GETÚLIO VARGAS. Mapa da exclusão digital. São Paulo, 2003. Disponível em:

<http://www2.fgv.br/ibre/cps/mapa_exclusa o/Inicio.htm>. Acesso em: 09 jul. $20 \overline{0} 06$.

HOLANDA, Marcos Costa; ROSA, Antônio Lisboa Teles da; LOUREIRO, André Oliveira Ferreira et. al. O analfabetismo no Ceará: caracterização e tendências recentes. 
Instituto de Pesquisa e Estratégia Econômica do Ceará (IPECE). 2006. Disponível em:

$<$ http://www.ipece.ce.gov.br/publicacoes/no tas_tecnicas/NT_22.pdf>. Acesso em: 12 jul. 2006.

INDICADOR Nacional de Alfabetismo Funcional. Disponível em:

$<$ http://www.ipm.org.br/download/inaf05.pdf > Acesso em: 14 jul. 2006.

LEGEY, Liz Rejane; ALBAGLI, Sarita. Construindo a sociedade da informação no Brasil: uma nova agenda. DataGramaZero, v.1, n.5, out. 2000.

LÉVY, Pierre. A Inteligência Coletiva. São Paulo: Editora 34, 2000.

LOBO, Ana Paula. Brasil tem o pior desempenho trimestral do Indicador da Sociedade da Informação. Convergência digital. Disponível em:

<http://www.convergenciadigital.com.br/cgi/ cgilu-

a.exe/sys $/$ start. htm? infoid $=3346 \&$ sid $=3>$ Acesso em: 14 jul. 2006.

MATTELART, Armand. História da sociedade da informação. São Paulo: Loyola, 2002.

MCLUHAN, Marshall; FIORE, Quentim. The medium is the massage. New York: Bantam Books, 1967.

MIRANDA, Antônio; MENDONÇA, Ana Valéria Machado. Informação e desenvolvimento em uma sociedade digital. Inclusão Social, Brasília, v. 1, n. 2, p. 53-57, abr./set. 2006.

MORIN, Edgar. Introdução ao pensamento complexo. Lisboa: Instituto Pieget, 1991.

NEGROPONTE, Nicholas. A vida digital. São Paulo: Companhia das Letras, 1995.

NEHMY, Rosa Maria Quadros; PAIM, Isis. Repensando a sociedade da informação. Perspectivas em Ciência da Informação, Belo Horizonte, v. 7, n. 1, p. 9-21, jan./jun. 2002.
PROGRAMA eLAC 2007. Disponível em: $<$ http://www.cepal.org/socinfo/elac>. Acesso em: 19 ago. 2006.

PROJETO CASA BRASIL. Disponível em $<$ http://www.casabrasil.gov.br> Acesso em: 25 ago. 2006.

SILVA, Alzira Karla Araújo. A sociedade da informação e o acesso à educação: uma interface necessária a caminho da cidadania. Informação e Sociedade: Estudos, João Pessoa, v. 11, n. 2, p. 1-12, 2001.

TAKAHASHI, Tadao (Org.). Sociedade da Informação no Brasil: livro verde. Brasília: Ministério da Ciência e Tecnologia, 2000.

TOFFLER, Alvin. A terceira onda. 16. ed. Rio de Janeiro: Record, 1980.

VOGT, Carlos. Informação e simulacro. ComCiência: Revista eletrônica de Joprnalismo Científico, n. 18, mar. 2001. Disponível em:

$<$ http://www.comciencia.br/reportagens/soci nfo/info01.htm>. Acesso em: 08 jul. 2006.

WERTHEIN, J. A Sociedade da Informação e seus desafios. Ciência da Informação, Brasília, v. 29, n. 2, p. 71-77, maio/ago. 2000.

Fabiano Couto Corrêa da Silva Bacharel em Biblioteconomia (UFRGS) Mestrando em Ciência da Informação (UFSC) fabianocc@gmail.com 


\section{Title}

The educational and politcs dimensions of the Information Society

\begin{abstract}
It approaches the educational and the politics' dimensions of the information society, discussing this scenery of constant changes as a result of the information use through the new technologies, in particular the Internet. It shows the Green Book's Educational Thematic Group and the current view of the educational levels and information access in Brazil.
\end{abstract}

\section{Keywords}

Information Society; Education; Digital Inclusion; Information Technology; Green Book.

\section{Título}

Las dimensiones educacional y política de la sociedad de la información

\section{Resumen}

Presenta un abordaje sobre las dimensiones educacional y política de la sociedad de la información, mostrando un escenario de cambios constantes en el transcurso del uso de la información a través de las nuevas tecnologías, en especial internet. Resalta el Grupo Temático de Educación del Libro Verde y el actual panorama de los niveles educacionales en Brasil y de acceso a la información.

\section{Palabras Clave}

Sociedad de la Información; Educación; Inclusión Digital; Tecnología de la Información; Libro Verde.
Recebido em: 25.01.2007

Aceito em: 19.04.2007 